Short Term Fumigation with Nitric Oxide Gas in Air to Extend the Postharvest Life of Broccoli, Green Bean, and Bok Choy

\section{Soegiarto and R.B.H. Wills}

AdDitional Index words. Brassica olevacea, Phaseolus vulgaris, Brassica chinensis, NO uptake

Summary. Broccoli (Brassica olevacea) green bean (Phaseolus vulgaris), and bok choy (Brassica chinensis) were fumigated with nitric oxide (NO) gas in air or in nitrogen for 2 hours at 20 ${ }^{\circ} \mathrm{C}\left(68.0^{\circ} \mathrm{F}\right)$, then stored at $20^{\circ} \mathrm{C}$ in humidified air containing $0.1 \mu \mathrm{L} . \mathrm{L}^{-1}$ (ppm) ethylene. The postharvest life of all vegetables was extended by NO although the concentration of NO required and the magnitude of the extension varied between produce ranging from $14 \%$ for green bean to more than $50 \%$ for broccoli. NO uptake by produce from air was not significantly different than from nitrogen at the lower effective NO concentrations, but NO uptake was less from air at the highest concentration used for broccoli. Application of NO in an air atmosphere is considered a feasible, more convenient treatment regime for horticultural produce than use of a nitrogen atmosphere.

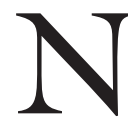
itric oxide is a free radical gas that was considered an industrial pollutant but is now known to be synthesized by humans with a major controlling role in numerous aspects of mammalian metabolism and is now used therapeutically to treat a range of conditions (Feldman et al., 1993). More recently, NO was found to also occur naturally in plants (Leshem and Haramaty, 1996). Leshem et al. (1998) reported a preliminary survey with six horticultural commodities and found that postharvest application of NO gas prolonged the postharvest life of produce. Wills et al. (2000a)

School of Applied Sciences, University of Newcastle, PO Box 127, Ourimbah, NSW 2258, Australia. conducted a more comprehensive study with strawberries (Fragaria $x$ ananassa) and found that fumigation with $5-10 \mu \mathrm{L} \cdot \mathrm{L}^{-1} \mathrm{NO}$ gas for $2 \mathrm{~h}$ gave maximal extension of postharvest life at 20 and $5^{\circ} \mathrm{C}\left(68.0\right.$ and $\left.41.0^{\circ} \mathrm{F}\right)$ of about $50 \%$ over untreated fruit. In both studies, produce were fumigated with $\mathrm{NO}$ in a nitrogen atmosphere due to the reported short half-life of $\mathrm{NO}$ in an air atmosphere due to its rapid oxidation to nitrogen dioxide (Snyder, 1992). However, the reaction of $\mathrm{NO}$ with air is a third order reaction and the half-life is thus dependent on both the concentration of oxygen and NO (Pleiffer et al., 1999). Soegiarto et al. (2003) examined the rate of degradation of NO at the relatively low concentrations found effective in extending postharvest life in atmospheres containing oxygen over the range $0.3 \%$ to $21 \%$. They found that the degradation of $30 \mu \mathrm{L} \cdot \mathrm{L}^{-1} \mathrm{NO}$ in air was much lower than expected with a half-life of $3.5 \mathrm{~h}$ and retention of two-thirds of the original NO after $2 \mathrm{~h}$. This suggests that it may be a feasible option to fumigate produce in an air atmosphere, a technique that would be more acceptable for both laboratory and commercial use. This paper investigated the effect of fumigation with $\mathrm{NO}$ gas in air and nitrogen $(<1 \%$ oxygen) on the postharvest life and NO uptake of the green vegetables, broccoli, green bean, and bok choy. Preliminary studies determined the range of NO concentration that was effective on individual produce.

\section{Materials and methods}

Broccoli, green bean, and bok choy were obtained from farms on Sydney-Central Coast region of New South Wales, Australia. Produce pieces of similar size, uniform green color, and free from deterioration were selected and randomly distributed into experimental units of about $100 \mathrm{~g}(3.5 \mathrm{oz})$ that were placed in a sealed 4-L (1.1 gal) plastic container. Each treatment comprised three experimental units. Each experiment was replicated with produce obtained on three different occasions. Containers to be fumigated in a nitrogen atmosphere were flushed with humidified nitrogen gas at 825 $\mathrm{mL} \cdot \mathrm{min}^{-1}(27.9 \mathrm{fl} \mathrm{oz} / \mathrm{min})$ for about $\mathrm{l}$ h to displace the oxygen. The NO concentrations used were 100-4000 $\mu \mathrm{L} \cdot \mathrm{L}^{-1}$ for broccoli, $50-100 \mu \mathrm{L} \cdot \mathrm{L}^{-1}$ for green bean and $10-50 \mu \mathrm{L} \cdot \mathrm{L}^{-1}$ for bok choy. NO in the range of 10-100 $\mu \mathrm{L} \cdot \mathrm{L}^{-1}$ was obtained by injecting an aliquot of gas from a cylinder of $\mathrm{NO}$ in nitrogen $\left(4380 \pm 180 \mu \mathrm{L} \cdot \mathrm{L}^{-1}\right)$ (BOC Gases, Sydney). For NO concentrations $>100 \mu \mathrm{L} \cdot \mathrm{L}^{-1}$, the containers were flushed with gas directly from the NO cylinder at $\mathrm{l} \mathrm{L} \cdot \mathrm{min}^{-1}(0.26 \mathrm{gal} / \mathrm{min})$ until the required concentration of $\mathrm{NO}$ in the container was achieved. Substantial flushing was required to achieve a concentration of 4000 $\mu \mathrm{L} \cdot \mathrm{L}^{-1}$. The containers were then sealed for $2 \mathrm{~h}$ after which the produce was stored at $20^{\circ} \mathrm{C}$ in a flowing stream $\left[20 \mathrm{~L} \cdot \mathrm{h}^{-1}(5.3 \mathrm{gal} / \mathrm{h})\right]$ of humidified air containing $0.1 \mu \mathrm{L} \cdot \mathrm{L}^{-1}$ ethylene. Ethylene was added to the air stream to simulate likely commercial storage conditions (Wills et al., 2000b). Two control treatments were included in each experiment comprising a unit of produce held in an air and a nitrogen atmosphere. Containers without produce were also included for each $\mathrm{NO}$ concentration in order to determine the physical loss of NO during the 2 $\mathrm{h}$ fumigation period.

The quality of vegetables was assessed daily when each piece of produce was repeatedly ranked subjectively from 1 to 5 , where $5=$ fresh and green; $4=$ $<10 \%$ yellowing/browning; $3=10 \%$ to $30 \%$ yellowing/browning and/or slight rotting or wilting; $2=30 \%$ to $50 \%$ yellowing/browning and/or moderate rotting or wilting; and $1=$ $>50 \%$ yellowing/browning and/or severe rotting or wilting. The mean value of the score assigned to all pieces in a treatment unit was calculated. Produce were rated until the score for individual pieces had declined to score 1 , or the mean value of the treatment unit had declined to 3.0. A linear regression of the change in the mean score of each unit against storage time was determined and the time for quality to decline to a mean score of 3.0 was calculated from the equation and assigned as the postharvest life for the produce in that unit.

Residual NO gas in the atmosphere at the end of fumigation period was measured using an ISO-NO Mark II meter (World Precision Instruments, Sarasota, Fla.) equipped with an ISO-NO P200 sensor. The NO uptake by produce was determined by difference between the loss of $\mathrm{NO}$ in the presence and absence of produce. The postharvest life and NO uptake were subjected to analysis of variance. 
Table 1. Postharvest life of broccoli, green bean and bok choy fumigated for $2 \mathrm{~h}$ at $20^{\circ} \mathrm{C}\left(68.0^{\circ} \mathrm{F}\right)$ with nitric oxide (NO) in air and nitrogen $\left(\mathrm{N}_{2}\right)$ followed by storage in $20^{\circ} \mathrm{C}$ humidified air containing $0.1 \mu \mathrm{L} \cdot \mathrm{L}^{-1}(\mathrm{ppm})$ ethylene.

\begin{tabular}{|c|c|c|c|c|c|c|}
\hline \multirow{3}{*}{$\begin{array}{l}\text { NO } \\
\text { concn } \\
\left(\mu \mathrm{L} \cdot \mathrm{L}^{-1}\right) \\
\end{array}$} & \multicolumn{6}{|c|}{ Postharvest life (d) } \\
\hline & \multicolumn{2}{|c|}{ Broccoli } & \multicolumn{2}{|c|}{ Green bean } & \multicolumn{2}{|c|}{ Bok choy } \\
\hline & Air & $\mathbf{N}_{2}$ & Air & $\mathbf{N}_{2}$ & Air & $\mathrm{N}_{2}$ \\
\hline $\begin{array}{l}0 \\
10\end{array}$ & $2.4 \mathrm{a}^{\mathrm{z}}$ & $2.4 \mathrm{a}$ & $7.9 \mathrm{a}$ & $8.0 \mathrm{a}$ & $\begin{array}{l}3.0 \mathrm{a} \\
3.6 \mathrm{ab}\end{array}$ & $\begin{array}{l}3.0 \mathrm{a} \\
3.3 \mathrm{ab}\end{array}$ \\
\hline 50 & & & $8.8 \mathrm{bc}$ & $8.5 \mathrm{~b}$ & $3.9 \mathrm{~b}$ & $3.7 \mathrm{~b}$ \\
\hline 100 & $2.4 \mathrm{a}$ & $2.4 \mathrm{a}$ & $9.0 \mathrm{c}$ & $8.5 \mathrm{~b}$ & & \\
\hline 2000 & $3.3 \mathrm{~b}$ & $3.8 \mathrm{c}$ & & & & \\
\hline 4000 & $3.6 \mathrm{bc}$ & $3.8 \mathrm{c}$ & & & & \\
\hline
\end{tabular}

${ }^{2}$ Values are the mean of three replicates with three treatment units each with about $100 \mathrm{~g} \mathrm{(3.5}$ $\mathrm{oz}$ ) of produce. Values within each produce followed by the same letter are not significantly different at $P<0.05$.

Least significance differences (LSD) at $P<0.05$ were calculated to compare differences between means.

\section{Results and discussion}

The data in Table 1 show the postharvest life of broccoli at $20^{\circ} \mathrm{C}$ following fumigation with $\mathrm{NO}$ in air and nitrogen. Postharvest life at $20{ }^{\circ} \mathrm{C}$ was significantly increased with 2000 and $4000 \mu \mathrm{L} \cdot \mathrm{L}^{-1}$ $\mathrm{NO}$ in both nitrogen and air but at the higher concentration, fumigation in nitrogen was significantly greater than in air. There was no significant effect of $100 \mu \mathrm{L} \cdot \mathrm{L}^{-1} \mathrm{NO}$ and there was no difference between the air and nitrogen control treatments. The increased postharvest life at 2000 and $4000 \mu \mathrm{L} \cdot \mathrm{L}^{-1} \mathrm{NO}$ was due to delayed yellowing although slight browning occurred on the surface of some florets.

The effectiveness of $\mathrm{NO}$ concentrations in the range 500 to $4000 \mu \mathrm{L} \cdot \mathrm{L}^{-1}$ in air was examined in a further study and the data in Table 2 confirm that all NO concentrations significantly increased postharvest life compared to untreated produce with the extension ranging from about $20 \%$ to $70 \%$. Slight browning again occurred on florets fumigated with 2000 and $4000 \mu \mathrm{L} \cdot \mathrm{L}^{-1} \mathrm{NO}$, although they remained at an acceptable condition for a longer period than control broccoli. The use of $1000 \mu \mathrm{L} \cdot \mathrm{L}^{-1}$ did not induce browning and resulted in about $40 \%$ increase in postharvest life.

Green bean was fumigated with $\mathrm{NO}$ at 50 and $100 \mu \mathrm{L} \cdot \mathrm{L}^{-1}$ and bok choy with 10 and $50 \mu \mathrm{L} \cdot \mathrm{L}^{-1}$ in air and nitrogen. The data in Table 1 show that the postharvest life of green bean at $20{ }^{\circ} \mathrm{C}$ was significantly $(P<0.05)$ extended by $\mathrm{NO}$ in both air and nitrogen due to reduced yellowing, but there was no significant difference between fumigation with air and nitrogen. The postharvest life of bok choy was significantly extended with the addition of $50 \mu \mathrm{L} \cdot \mathrm{L}^{-1}$ NO with no significant difference between fumigation in air and nitrogen. The end of postharvest life for both produce was the appearance of yellowing.

Measurement of residual NO gas in the atmosphere at the end of fumigation period indicated that NO loss was greater in the presence of produce (data not shown) and the increased loss of NO was considered due to NO uptake by produce. The NO
Table 2. Postharvest life of broccoli fumigated at $20^{\circ} \mathrm{C}\left(68.0{ }^{\circ} \mathrm{F}\right)$ with nitric oxide (NO) gas in air followed by storage in $20^{\circ} \mathrm{C}$ humidified air containing $0.1 \mu \mathrm{L} \cdot \mathrm{L}^{-1}(\mathrm{ppm})$ ethylene.

\begin{tabular}{lc}
\hline NO concn & Postharvest \\
$\left(\mu \mathrm{L} \cdot \mathrm{L}^{-1}\right)$ & life $(\mathrm{d})$ \\
\hline
\end{tabular}

$\begin{array}{ll}0 & 2.2 \mathrm{a}^{\mathrm{z}} \\ 500 & 2.6 \mathrm{~b} \\ 1000 & 3.0 \mathrm{c} \\ 2000 & 3.4 \mathrm{~d} \\ 4000 & 3.8 \mathrm{e}\end{array}$

${ }^{2}$ Values are the mean of three replicates with three treatment units each of four florets weighing about $100 \mathrm{~g}(3.5 \mathrm{oz})$. Values followed by the same letter are not significantly different at $P<0.05$.

$2.2 \mathrm{a}^{\mathrm{z}}$
$2.6 \mathrm{~b}$
$3.0 \mathrm{c}$
$3.4 \mathrm{~d}$
$3.8 \mathrm{e}$
ee replicates with three
florets weighing about
< by the same letter are
$<0.05$.
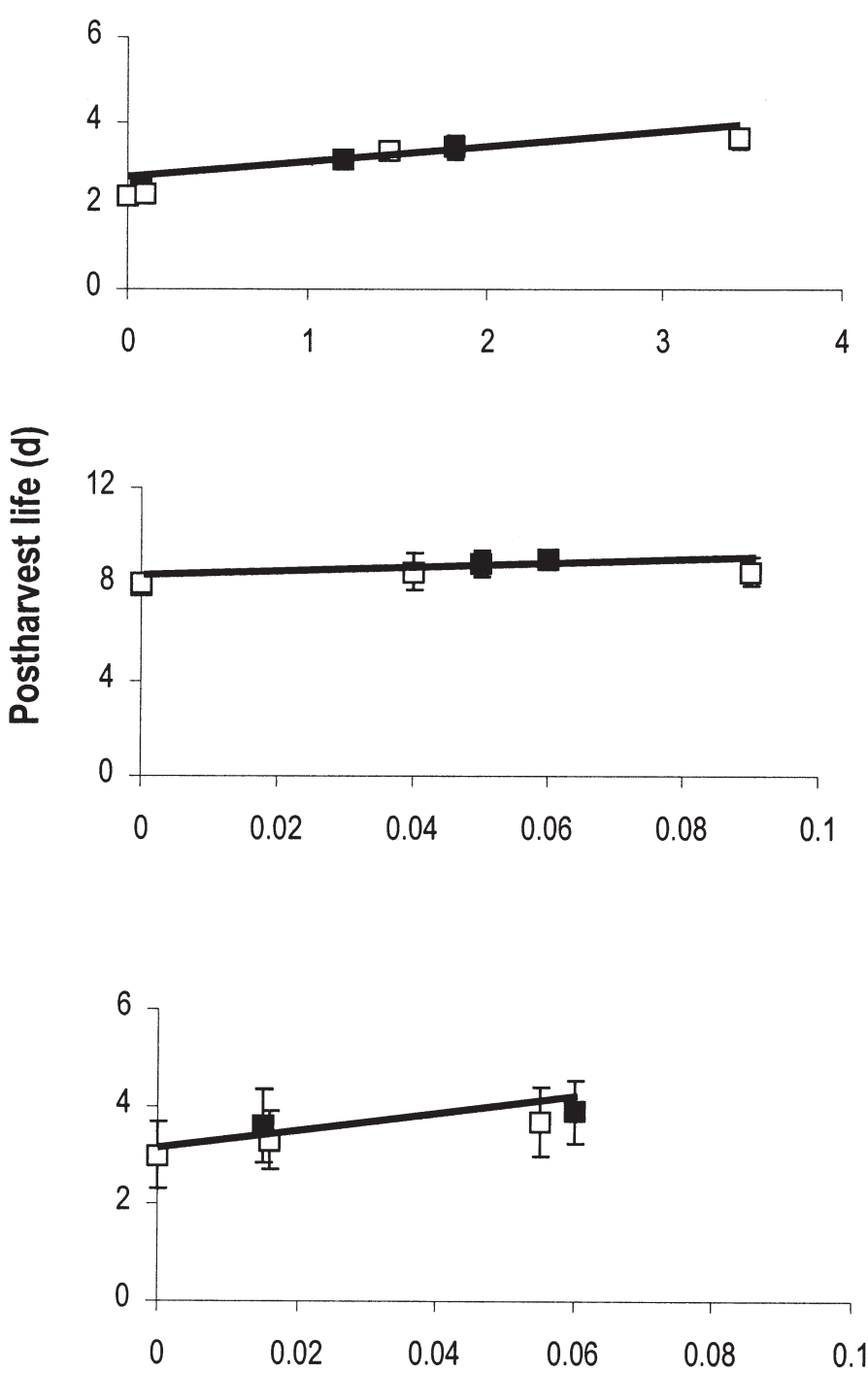

\section{NO uptake $\left(\mu\right.$ mole. $\left.g^{-1}\right)$}

Fig. 1. Relationship between nitric oxide (NO) uptake and postharvest life of broccoli, green bean, and bok choy treated in air (ם) and in nitrogen $(\square)$, followed by storage at $20^{\circ} \mathrm{C}\left(68.0^{\circ} \mathrm{F}\right)$ in humidified air containing $0.1 \mu \mathrm{L} \cdot \mathrm{L}^{-1}(\mathrm{ppm})$ ethylene. 
uptake by produce was then calculated by difference. Figure 1 shows that the increase in postharvest life of each produce was linearly related to increased NO uptake [for broccoli, y $=2.46+0.41 \times(P<0.001)$; for green bean, $\mathrm{y}=7.94+11.9 \mathrm{x}(P<0.001)$; for bok choy, $\mathrm{y}=3.11+11.27 \mathrm{x}(P<$ $0.05)]$. It also shows that there was little difference in NO uptake in air and nitrogen at the lower concentrations. The greatest difference in uptake was for fumigation of broccoli with 4000 $\mu \mathrm{L} \cdot \mathrm{L}^{-1} \mathrm{NO}$ where the use of nitrogen gave a significantly higher uptake $(P$ $<0.01)$ than air. This is presumably due to a higher degradation rate of the relatively high concentration of $\mathrm{NO}$ in air so that effectively a lower concentration was available to be absorbed by the produce. The nonsignificant difference in rate of loss between air and nitrogen at the lower NO concentrations was presumably due to the slower degradation rate of $\mathrm{NO}$ in the $21 \%$ oxygen (Tsukahara et al., 1999).

It is concluded, first, that shortterm fumigation of broccoli, green bean, and bok choy with NO is able to extend the postharvest life although the magnitude of the extension and the concentration of $\mathrm{NO}$ required varied substantially between produce. It is further concluded that, for most produce, the relatively low concentration of $\mathrm{NO}$ needed to extend postharvest life has a relatively slow rate of degradation in air. This makes it feasible to fumigate horticultural produce with $\mathrm{NO}$ gas in an air atmosphere. For produce, such as broccoli, where the concentration of $\mathrm{NO}$ needed is relatively high and some NO degradation occurs during the $2-\mathrm{h}$ fumigation period, the use of a slightly higher initial NO concentration would compensate for such loss. Further testing of produce used in this trial is needed to determined the consistency of effect across cultivars, seasons, and growing locations and on a wider range of vegetables to establish the extent of ubiquity. While no application has yet been made for commercial use of $\mathrm{NO}$, registration should be aided by the natural occurrence of $\mathrm{NO}$ in plants and mammals.

\section{Literature cited}

Feldman, P.L., O.W. Griffith, and D.J. Stuehr. 1993. The surprising life of nitric oxide. Chem. Eng. News 71:26-38.

Leshem, Y.Y. and E. Haramaty. 1996.

The characterization and contrasting effects of the nitric oxide free radical in vegetative stress and senescence of Pisum sativum Linn. foliage. J. Plant Physiol. 148:258-263.

Leshem, Y.Y., R.B.H. Wills, and V.V.V. $\mathrm{Ku}$. 1998. Evidence for the function of the free radical gas-nitric oxide $\left(\mathrm{NO}^{*}\right)$ - as an endogenous maturation senescence regulating factor in higher plants. Plant Physiol. Biochem. 36:825-833.

Pleiffer, S., B. Mayer, and B. Hemmens. 1999. Nitric oxide: Chemical puzzles posed by a biological messenger. Angewandte Chem. Intl. Educ. 38:1714-1731.

Snyder, S.H. 1992. Nitric oxide: First in a new class of neurotransmitters. Science 257:494-496.

Soegiarto, L., R.B.H. Wills, J.A. Seberry, and Y.Y. Leshem. 2003. Nitric oxide degradation in oxygen atmospheres and rate of uptake by horticultural produce. Postharvest Biol. Technol. 28:327-332.

Tsukahara, H., T. Ishida, and M. Mayumi. 1999. Gas-phase oxidation of nitric oxide: Chemical kinetics and rate constant. Nitric Oxide: Biol. Chem. 3:191-198.

Wills, R.B.H., V.V.V. Ku, and Y.Y. Leshem. 2000a. Fumigation with nitric oxide to extend the postharvest life of strawberries. Postharvest Biol. Technol. 18:75-79.

Wills, R.B.H., M.A. Warton, and V.V.V. Ku. $2000 \mathrm{~b}$. Ethylene levels associated with fruit and vegetables during marketing. Austral. J. Expt. Agr. 40:465-470. 